Revista Brasileira de Odontologia Legal - RBOL

\title{
Balística Forense
}

\section{LESÕES TÍPICAS E SEUS EPÔNIMOS EM BALÍSTICA FORENSE}

\section{Typical wounds and your eponyms in forensic ballistics}

Carlos Henrique DURÃO ${ }^{1,2}$; Marcos Paulo Salles MACHADO ${ }^{3}$.

1. Perito Médico Legista do Instituto Nacional de Medicina Legal e Ciências Forenses, Lisboa, Portugal.

2. Médico especialista em Ortopedia e Traumatologia, Assistente Hospitalar do Hospital Vila Franca de Xira, Lisboa, Portugal.

3. Perito legista do Instituto Médico-Legal Afrânio Peixoto, Rio de Janeiro, Brasil.

Informação sobre o artigo

Recebido: 24 Mar 2015

Aceito em: 20 Dez 2015

\section{Autor para correspondência}

Carlos Henrique Durão

Hospital Vila Franca de Xira. Estrada nacional n 1. Povos.

Vila Franca de Xira, Lisboa. Portugal. 2600-000.

Email: drcarlosdurao@hotmail.com.

\section{RESUMO}

Os epônimos são parte da história da Medicina e representam, sobretudo, uma homenagem aos pioneiros na descrição de um sinal, doença, técnica, manobra ou estrutura anatômica. Este trabalho tem como objetivo revisar a literatura médico-legal clássica e apresentar epônimos referentes aos resultados mais significativos da balística terminal. Os epônimos podem facilitar a comunicação entre os peritos, encurtando a descrição, mas não deve ser utilizado em relatórios que irão ser lido por leigos, uma vez que o seu uso neste caso, poderia conduzir à confusão de termos.

\section{PALAVRAS-CHAVE}

Epônimos; Medicina Legal; Balística Forense, Ferimentos por Arma de Fogo.

\section{INTRODUÇÃO}

Os epônimos (do grego eponymos - "sobre o nome") fazem parte da história da Medicina e representam, na sua maioria, uma justa homenagem aos pioneiros na descrição de um sinal, doença, técnica, manobra ou estrutura anatômica ${ }^{1}$.

Quem nunca ouviu falar da doença de Alzheimer, da tríade de Virchow ou do Bacilo de Koch? Mas nem todos conhecem o Funil de 
Bonnet, a Regra de Puppe, o Sinal de Benassi ou Werkgaertner ${ }^{2}$. O seu conhecimento, além de justa homenagem é um diferencial no ensino clássico da Medicina Legal.

É notória a influência da escola médico-legal alemã e francesa na atribuição dos epônimos, sendo por vezes, questionada ou mesmo ignorada na literatura de origem anglo-saxônica ${ }^{1}$ sem deixar de reconhecer o valor da sua tradução.

Neste contexto, este trabalho tem como objetivo identificar e apresentar os mais significativos achados da balística terminal na prática médico-legal, bem como seus epônimos, por meio da revisão das principais obras literárias médico-legais.

\section{BALÍSTICA FORENSE E SEUS EPÔNIMOS}

Em balística terminal, ou balística dos efeitos, a observação do ferimento de entrada e de saída dos projéteis de arma de fogo assim como o seu trajeto é fundamental. A estimativa da distância do disparo pode ser determinante no esclarecimento da morte.
Feridas de entrada nos tiros encostados, com planos ósseos logo abaixo, tem forma irregular, larga, com entalhes e lacerações, devido à ação resultante dos gases que descolam e afastam os tecidos. Isto porque os gases da explosão penetram na ferida e refluem ao encontrar a resistência do plano ósseo. É frequente na região frontal ou esternal, e é chamada de Boca de mina de Hoffman ${ }^{2,3,7,11-16}$ (Figura1).

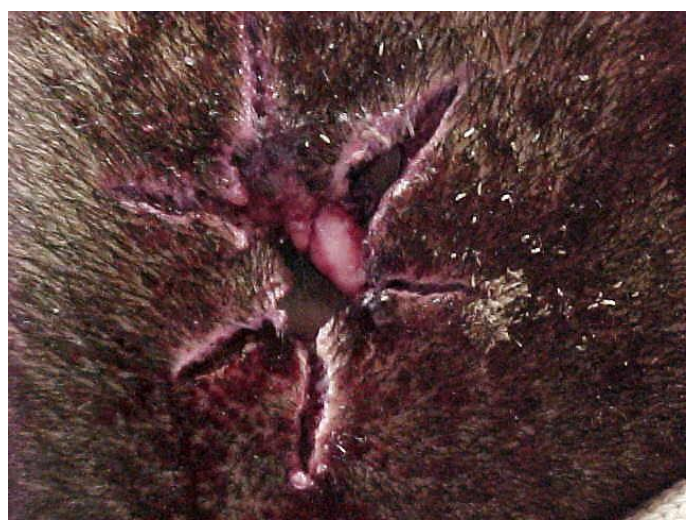

Figura 1. Boca de mina de Hoffmann. Ferida estrelada com bordas viradas para fora com saída de tecido encefálico. Tiro com cano encostado.

Este mesmo padrão é observado na roupa, que tende a rasgar-se em forma de cruz, conhecido como o Sinal da Cruz de Rojas $^{2,13}$ (Figura 2). Normalmente não há zona de tatuagem no exterior já que os elementos do GSR (Gunshot Residues - GSR) seguem ferida adiante. A deposição destes resíduos no osso formando 
um halo "fuliginoso" ou de "fumo", é o Sinal de Benassi ${ }^{9,12,13}$ (Figura 3), sua presença permite reconhecer uma ferida de entrada com cano encostado. Pode ainda ser caracterizado o Sinal do Schusskano ${ }^{3,13}$ (Figura 4), traduzido pela impregnação do GSR nas paredes do trajeto produzido pelo projétil, entre as lâminas internas e externas dos ossos do crânio. Armas que possuem aberturas laterais ou superiores no cano, como os compensadores de recuo, ou tapa-chamas, tendem a ter outro padrão ${ }^{16}$.

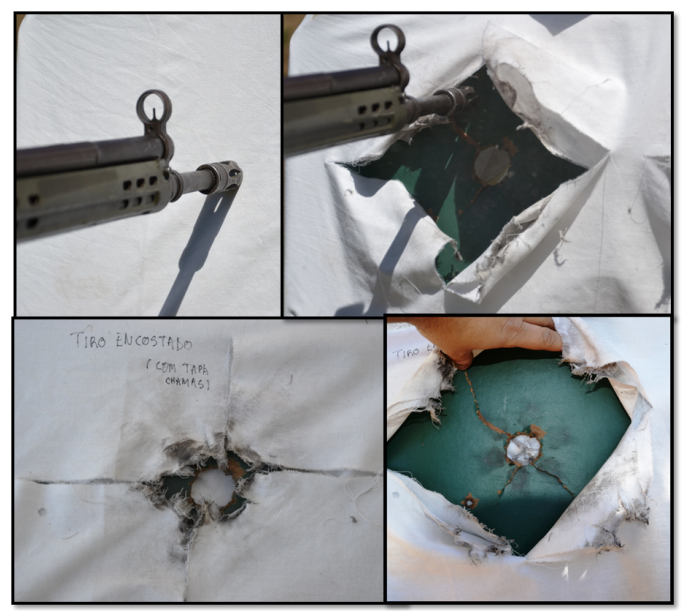

Figura 2. Ensaio balístico (com fuzil G3 - 7,62mm) efetuando tiro encostado contra tecido industrializado (lençol) para demonstrar o rasgo da "Cruz de Rojas" e o padrão do GSR pelas raias do "quebra chamas" do cano da arma.

Os tiros encostados ainda podem deixar impresso na pele 0 chamado Sinal de Werkgaertner (Figura 5), que consistiria na presença de escoriações junto ao orifício de entrada e que são produzidas na consequência do embate violento da pele contra o cano da arma, devido a ação de dentro para fora dos gases de explosão e que podem mesmo reproduzir a forma do cano da arma $^{3,13}$. Entretanto, Miranda ${ }^{14}$ realizou uma série de experimentos balísticos com tiros encostados em diversos alvos de tecido industrializado, constatando a queima das fibras destes e concluindo que o Sinal de Werkgaertner é uma queimadura e não uma escoriação.

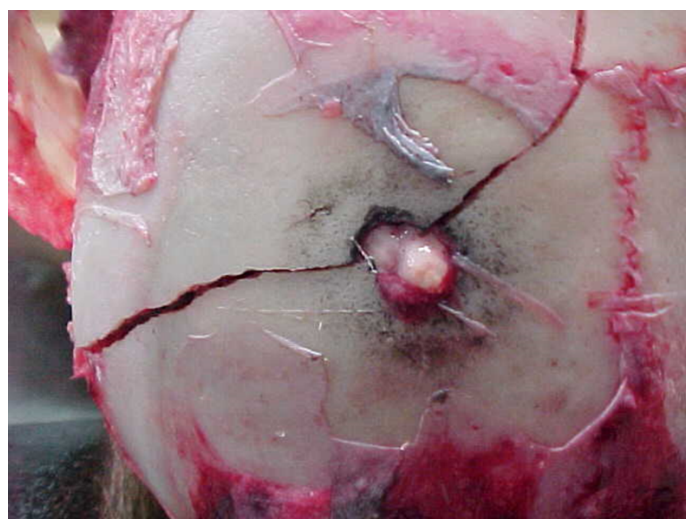

Figura 3. Sinal de Benassi. Mesmo caso da figura 1. Deposição dos elementos do GSR junto ao plano ósseo. Tiro encostado.

O projétil de arma de fogo tem uma ação perfurocontundente $\mathrm{e}$ pode ser mais ou menos perfurante, consoante sua forma. Projéteis militares de alta energia tendem a ser mais perfurantes e a deixarem 
microlacerações, como descreve Di Maio ${ }^{4}$. Ao vencer a elasticidade da pele durante sua passagem, 0 projétil produz uma Orla de contusão (de Thoinot) ${ }^{13}$, às vezes apergaminhada pela desidratação da escoriação gerada pelo atrito do projétil com a pele. Neste atrito podem ficar retidas sujidades contidas no projétil, numa orla denominada dirt ring ${ }^{4}$, Orla de exugo $8,9,11,12,13,14$, collerete $d^{\prime}$ essuyage ${ }^{11}$ ou Orla de Chavigny $^{13}$.

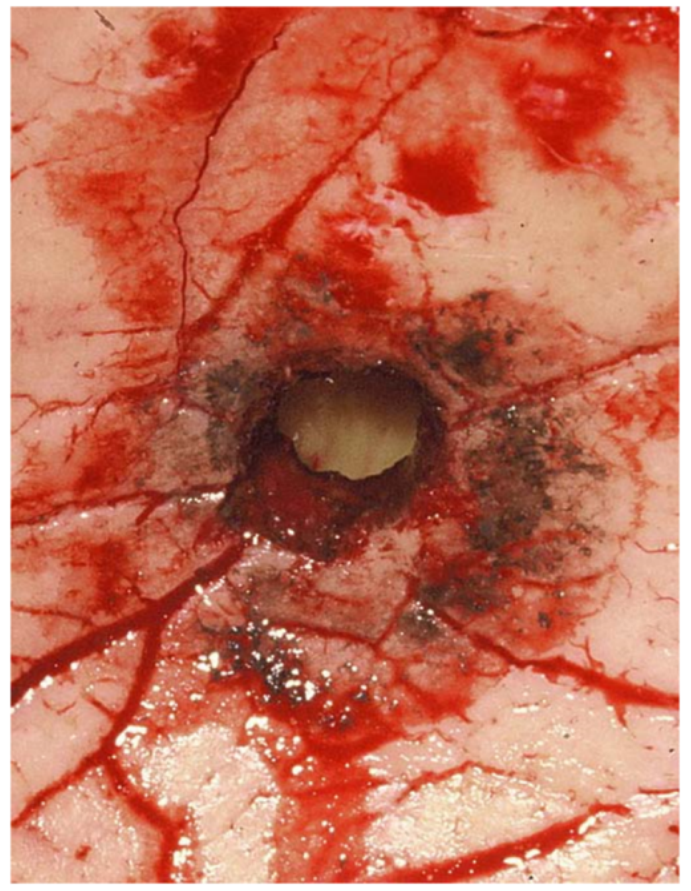

Figura 4. Sinal do "Schusskanol". Notar a impregnação do GSR nas paredes do trajeto produzido pelo projétil na lâmina interna do crânio. Vista do interior da tábua óssea.

$$
\text { O traumatismo do projétil }
$$

com os capilares adjacentes promove uma hemorragia, dando origem a uma orla equimótica ${ }^{6-15}$, que pode estar ausente em tiros post mortem. As orlas de contusão, de enxugo e equimótica são originadas pelo impacto do projétil (efeito primário).

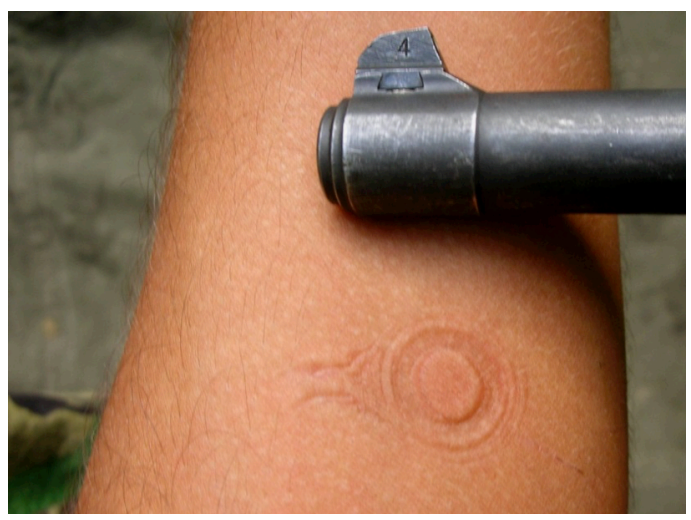

Figura 5. Reprodução da marca do cano da arma (pistola 9.mm Walter p38) após ligeira pressão no antebraço do autor - simulação do Sinal de Werkgaertner.

Os efeitos secundários são oriundos da deposição dos variados elementos do GSR na ferida e vão depender da distância do cano da arma à vítima, estando ausentes nos tiros a longa distância. Fica clara a importância do exame das vestes, já que diversos elementos do GSR podem ficar retidos em vários planos, deixando na ferida um Sinal do decalque $e^{2,13}$, relacionado ao tecido da roupa, ou uma tatuagem en cocarde de Simonin $^{2,11,13}$.

A forma do orifício de entrada, com suas orlas e 
elementos secundários, (GSR) são importantes para a determinação da direção do tiro. Nos ossos chatos (como no crânio) o orifício tem sempre menor diâmetro no plano que em é atravessado inicialmente, de modo que a fratura tem a forma de um tronco de cone que se alarga no sentido do trajeto, à semelhança de um funil invertido, este é o Sinal do Funil de Bonnet ${ }^{2,13}$ (Figuras $6 \mathrm{e}$ 7) . Nos tiros tangenciais que atingem o crânio, a fratura de entrada pode atingir a de saída formando uma única fratura com aspecto de buraco de fechadura ${ }^{4,5,6,13}$. Em tiros múltiplos é possível determinar a sua sequência quando um traço de fratura termina em noutro já existente. Isto é explicado pela dissipação da energia como sugere a Regra de Puppe ${ }^{1,2,3}$ (Figura 8) .

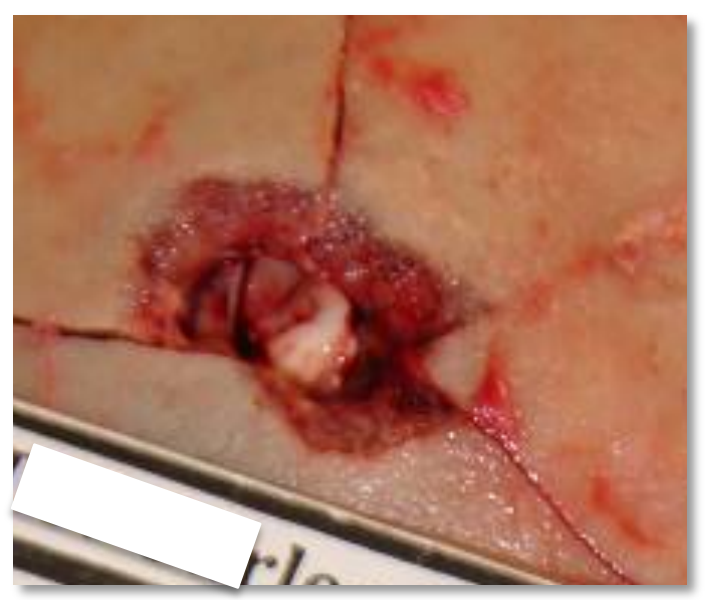

Figura 6. Orifício de saída de projétil de arma de fogo.
Os orifícios de saída, em geral, têm forma irregular, de diâmetro maior, com bordas voltadas para fora e sem os elementos secundários do GSR. A orla de contusão, excepcionalmente, pode aparecer, quando à saída do projétil existe um obstáculo resistente, este é o Sinal de Romanese ${ }^{11,13}$.

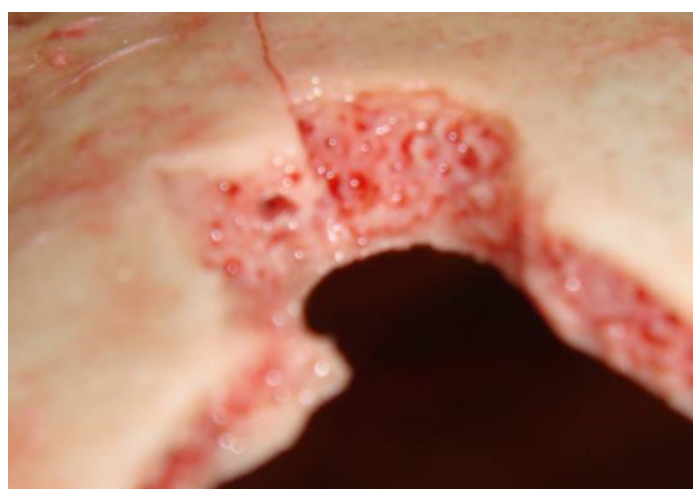

Figura 7. Detalhe da fratura em bisel do orifício de saída do projétil de arma de fogo (Sinal do funil de Bonnet). Mesmo caso da Figura 6.

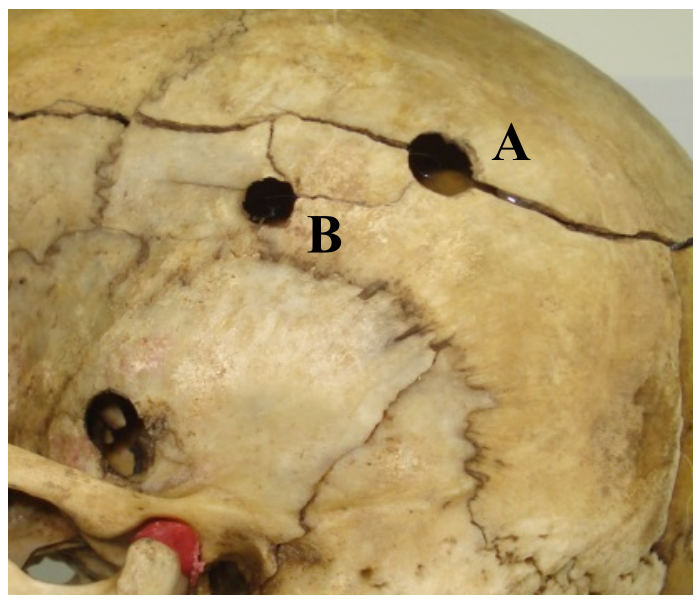

Figura 8. Três orifícios de entrada de projéteis de arma de fogo. Pela "Regra de Puppe" é possível concluir que o orifício "A" é anterior ao orifício "B". 


\section{CONSIDERAÇÕES FINAIS}

O progresso na balística é constante. Munições modernas, que combinam o desenvolvimento de novas cargas propelentes com os mais variados projéteis para diferentes fins, têm modificado as características das feridas ao longo das décadas. Os epônimos refletem as condições históricas $e$ as limitações técnicas do período em que foram descritos. Grande parte deles será mesmo ultrapassado e cairá no esquecimento. Outros permanecerão.

Epônimos podem facilitar a comunicação entre os peritos, abreviando descrições e contribuindo com o ensino erudito da matéria, mas não devem ser usados indiscriminadamente nos relatórios periciais criminais, que em regra serão lidos por magistrados que por norma desconhecem a linguagem técnica própria da Medicina. O seu uso neste caso, poderá gerar grande confusão, lembrando que mesmo entre diversas escolas médico-legais, os epônimos não são consensuais e o seu uso em relatórios internacionais é mesmo raro. As lesões devem ser bem documentadas e descritas, permitindo assim, que possam ser interpretadas por outros peritos a qualquer momento.

\begin{abstract}
The eponyms are part of the history of medicine and represent mostly a tribute to the pioneers in the description of a sign, disease, technique, maneuver or anatomical structure. This work aims to present the most significant findings of ballistics terminal. Eponyms may facilitate communication between experts, shortening the description, but should not be used in reports, which will be read by lay people, since its use in this case, could lead to confusion.
\end{abstract}

\title{
KEYWORDS
}

Eponyms, Forensic Medicine, Forensic Ballistics, Gunshot Wounds.

\section{REFERÊNCIAS}

1. Necas P, Hejna P. Eponyms in http://dx.doi.org/ 10.1007/s12024-012forensic pathology. Forensic Sci Med 9328-z.

Pathol. 2012; 8(4): 395-401. DOI: 
2. Costeira O. Dicionário brasileiro de epônimos em medicina. São Paulo: Editora Unifesp; 2010.

3. Kneubuehl B. Wound ballistics - basics and applications. Springer. 2011.

4. Di Maio VJM. Gunshot Wounds. 2 Ed. CRC Press; 1999.

5. Saukko $P$, Knight $B$. Forensic pathology. London: A Hodder Arnold Publication; 2004.

6. Spitz WU. Spitz and Fisher's medicolegal investigation of death. Springfield: Charles C Thomas Publisher; 2006.

7. Strassmann F, Carrara M. Manuale di Medicina Legale. Torino: Unione tipografico- editrice; 1901.

8. Simonin C. Medicina Legal Judicial. Barcelona: Editorial Jims; 1962.
9. Bonnet EFP. Lecciones de Medicina Legal. 3 ed. Buenos Aires: Lopez Libreros; 1978.

10. Vieira $A X L$. Medicina judiciária e pericial: jurisprudência médica. Coimbra: Imprensa da Universidade; 1908.

11. Lopes CRS. Guia de perícias MédicoLegais. 3 ed. Braga: Livraria Cruz; 1958.

12. Fávero F. Medicina Legal, 10 ed. São Paulo: Itatiaia; 1975.

13. França GV. Medicina Legal. 9 ed. Rio de Janeiro: Guanabara Koogan; 2011.

14. Miranda LI. Balística Forense. Rio de Janeiro: Rúbio; 2014.

15. Hércules HC. Medicina Legal - texto e atlas. Rio de Janeiro: Atheneu; 2005.

16. Calabuig JAG, Cañadas EV. Medicina Legal y Toxicología. 6 ed. Madrid: Masson; 2005. 